\title{
Combination of Bilingual Teaching and Open Education for Laboratory in Engineering Education
}

\author{
Haiyan $\mathrm{Du}^{1, \mathrm{a}}$,Weiming $\mathrm{Wu}^{2, \mathrm{~b}}$,Yang $\mathrm{Li}^{1, \mathrm{c}}$, Zhijian Shen ${ }^{1, \mathrm{~d}}$ \\ ${ }^{1}$ School of Metallurgical and Chemical Engineering Jiangxi University of Science and \\ Technology,Ganzhou,341000, China \\ ${ }^{2}$ Institute of Engineering Research Jiangxi University of Science and Technology, \\ Ganzhou, 341000,China

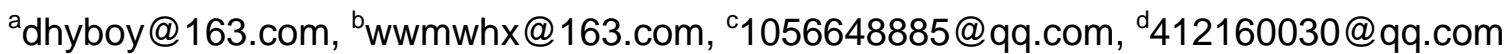

Keywords: Bilingual Teaching; Open Education; Laboratory; Engineering Education

\begin{abstract}
This paper explores the significance and present situation of open education for laboratory in engineering education, describes the effect of bilingual teaching during the education reform in modern society, discusses the feasibility of the combination of bilingual teaching and open education for laboratory in engineering education, as well as the significance of the combination and the impact on education reform. The practical application of the combination indicates that the close combination can complement and promote each other, and can not only exert the teaching and learning initiative of teachers and students and the hardware function of laboratory to the utmost extent, but also improve the quality of engineering education.
\end{abstract}

\section{Introduction}

With the deepening of international trade and investment, the world economy has been accelerating to develop towards the direction of integration. Because of China's accession to the WTO, China is in the face of more frequent international exchanges and challenges from competitors all over the world. That leads to a higher demand not only on the 21 century talent, but also on the development of education in China.

The bilingual education in new era came into being, which is not only significant but also vast pressing. The Chinese Ministry of Education had introduced a new policy in 2001, which explicitly requires universities to carry out bilingual education actively. The Policy document points out that according to the requirements of education being modernization-oriented, world-oriented, and future-oriented, undergraduate education should create conditions for the use of English and other foreign languages in the teaching of public courses and specialized courses, in order to meet the challenges of economic globalization and technological revolution, and the bilingual education strategies such as some first some after, some anxious some slow, gradual implementation, step-by-step, etc, are pointed out for different school and specialty.

Practical skill training is an important part of the cultivation of innovative talents. Open education for laboratory is the effective expansion of experimental teaching in various disciplines. The open model of open-training-development provides a new attempt for the lab overall design of the management and operation system of open education. With the development of experimental teaching reform, the research of open education for laboratory will receive continuous concern of the experimental teaching departments and experimental teaching management department.

\section{Open Education for Laboratory in Engineering Education}

In engineering education, traditional classroom experimental teaching conducts only in limited time and space. Moreover, teaching objects, materials, equipment, assessment methods and other elements are fixed. When doing experiment, students just operate as the required steps mechanically, that is imitative to some extent. Most of the experiments are validation experiments. In this case, students accept the experimental task passively, lack of self-selection, do experiments only within 
the experimental framework for the deployment of teachers. That limits the students' enthusiasm and initiative, and is not conducive to bring up students' innovative spirit and practical ability and to improve the student's independent experimental capabilities, too[1].

As the main way to cultivate high-quality practice creative talents, experimental teaching is an important part of engineering education, and is an important means of fostering students' practical ability. Apart from making full use of the experimental equipment, more importantly, establishing open lab will stimulate and develop students' interest in experiment. It can urge students to complete thinking, operating, analyzing, and solving problem independently. Thus it can fully mobilize students' enthusiasm and initiative, and improve their self-development capabilities.[2] Open education for laboratory is one of the important means of experimental teaching reform, which can facilitate the promotion of laboratory construction and development in depth.

With the increasing demands of cultivation for innovative talents, the open education for laboratory is sustained. However, the open laboratory is not just a problem of time and space, but a management model, which involves the configuration and utilization of laboratory resources, the optimization of experimental workforce and the construction of management system.[3] The open education for laboratory is a systematic project and is subject to many factors. There are many problems such as the imperfect open laboratory management system, the enthusiasm of the students, the experimental teacher construction, the laboratory equipment maintenance and management and so on. The open education for laboratory can't copy other's model and experience. It is necessary to explore according to the actual situations.[4]

\section{Bilingual Teaching in Engineering Education}

Bilingual teaching was first emerged in the European and American countries at the beginning of 20th century. In 1960s, bilingual teaching became popular in some immigration countries in order to make immigrants or refugees integrate into local society faster. In the wake of globalization advancement and the intensification of international competition, international bilingual and multilingual education is increasingly subject to national attention in the mid and late of 1980s[5-7]. Bilingual teaching was first launched in China coastal areas, such as Beijing, Shanghai, Guangzhou and Shenzhen. In recent years, bilingual teaching is becoming more and more universal inland. In order to further promote the development of bilingual teaching, China's Ministry of Education started bilingual education model curriculum project in 2007.

Being a new teaching model, bilingual teaching has gradually become the focus of society and academia. Bilingual teaching is a teaching activity, which chooses mother tongue and one of foreign languages such as English as written and spoken media. Its obvious advantage is to earn language knowledge and professional knowledge combined organically, and to provide a strategic opportunity to speed up bilingual teacher's construction of colleges and universities, which is very helpful to accelerate the internationalization level of colleges and universities.

With the growing cooperation and interdependence between international trade and economy, the world economy is developing towards integration. Countries are frequently interacting with each other on various levels in political, economic, social and other fields. Thence the demand on the English language talent is growing. In conclusion, bilingual teaching is an inevitable trend of the teaching reform.

For example, in China after the students complete the basic English study in the first year or second year of college and pass College English Test 4(CET4) and College English Test 6(CET6), some specialized courses implements bilingual teaching with foreign materials, students can then quickly accept that and are integrated into the bilingual education model which may be transformed into pure English teaching in a later stage. That will play a role of four years of continuous English learning.

\section{Combination of Bilingual Teaching and Open Education for Laboratory}

The feasibility of combination: The engineering education in the education reform makes the 
combination of bilingual teaching and open education for laboratory possible. Open laboratory, spread out in the round, lends foundation for bilingual teaching in laboratory. Bilingual teaching can be more effective based on open education for laboratory. The open laboratory can provide adequate hardware support for bilingual teaching and bilingual teaching lets the open laboratory and the world trail connection. Both support each other for mutual promotion and common development and improvement.

Bilingual teaching can completely combine with open education for laboratory organically. Using bilingual teaching textbooks for the first time, the students will face a lot of new words and technical term in the initial stage. The introduction of open education for laboratory in the process of bilingual teaching will make students gain knowledge on their own initiative not passively [8]. Based on that, students are familiar with the laboratory instruments and professional process to a certain extent, bilingual teaching is easy to be accepted by students.

The Significance of combination: Only bilingual teaching combine with open education for laboratory, can it implement more effectively. Bilingual teaching in engineering education has been introduced into the laboratory, teachers can teach professional knowledge in English and in laboratory scene. By doing experiments in the lab, bilingual teachers will receive an interaction with students, and will explain professional knowledge and professional vocabulary in English through specific experimental equipment and phenomena. That leads bilingual teaching to be no longer boring but vivid, to arouse students' initiative, enthusiasm and innovation consciousness. It simultaneously expedites inspiring students' potential, enlightening students' thinking in the process of bilingual teaching.

On the other hand, combination makes full use of laboratory resources, experiment teaching methods become more abundant. Foreign language interaction between teachers and students, between students and students is easy to implement. The environment for students to take the initiative to express in a foreign language can be created easily. Students' interest in experiment is greatly enhanced, significant improvements in the experiment teaching is obvious.

The effect and benefit of combination: Facts show that the combination of bilingual teaching and open education for laboratory can be successful, taking the bilingual course "industrial analysis" as an example, offered to chemical engineering students in Jiangxi University of Science and Technology. Industrial analysis is a course based on industrial analysis technology, which is also known as the eye of industrial production. [9-10] Experimental teaching plays an important role in engineering education. There is a wealth of analytical equipment in the laboratory, most of them are from abroad, which contains detailed original foreign language material and information. It is apparently suitable and effective to conduct bilingual teaching in the open laboratory. It will enhance the utilization rate of laboratory equipment and government investment funds. Students can grasp the foreign forefront of development in the discipline, and the students' future employment will be supported greatly.

In the application of the combination of bilingual teaching and open education for laboratory, teachers provide students with appropriate guidance and strive to realize communication bilingually, that will greatly arouse students' learning interest and initiative and enthusiasm, and greatly improve the effect of bilingual teaching in industrial analysis. This combination can vividly reflect the latest information of industrial analysis. As a result, students contrive a kind of fast and effective new method to acquire knowledge.[11-12] And it plays an important role of demonstration and leading for the teaching reform of other courses.

\section{Conclusions}

In order to improve the quality of engineering education, to cultivate students to be adapted to the international environment and era, it is urgently necessary to provide students with a practice environment where the interest and ability of scientific research and innovation will be trained. In the practice environment, bilingual teaching and open education for laboratory are combined, bilingual expression of professional knowledge is consolidated. Through the combination of bilingual teaching and laboratory, students will get an open space for developing individual thinking 
advantage, exercising comprehensive skills and bilingual skills, thus students' comprehensive quality and international competitive power can be improved totally.

\section{Acknowledgment}

The authors would like to thank for the financial support by Education Department of Jiangxi Province in China. Educational reform project:

1. Integrated construction and development research of experimental teaching demonstration center of chemistry and chemical engineering. (Project Number: JXJG-08-6-16).

2. Quality engineering project: bilingual education model curriculum-industrial analysis.

\section{References}

[1] Alex Baker, Emily Oh Navarro, Andre van der Hoek, “An experimental card game for teaching software engineering processes, ” The Journal of Systems and Software, Vol.75, No.1-2, pp 3-16, 2005.

[2] Hiroyuki IshiiMotonori Ogura, Shunji Kurisu, Atsushi Komura, Atsuo Takanishi2, Naritoshi Iida, and Hiroshi Kimura, "Teaching model for intraoperative spinal sonography in spinal Fractures: An experimental" Archives of Orthopaedic and Trauma Surgery, Vol. 120, No. 3-4, pp 183-187, 2000.

[3] Cui Xiuli, Yao Lan, Wang Fengwei, “ Design and implementation of web-based open-laboratory management information system " The first International Workshop on Education Technology and Computer Science, Vol.1, pp. 980-982, 2009.

[4] Lu Ang, Fan Ying, Guan Zong qi, “An open laboratory automatic management system based on RFID, ” The 2nd International Conference on Computer and Automation Engineering (ICCAE), Vol.1, pp. 57-60, 2010.

[5] Nick Theobald, "Bilingual education: cause or cure?,” Department of Political Science Texas A\&M University, pp.1-25, 2008.

[6] Virginia Brunton, David Hall, "Evaluating the benefits of bilingual officers in providing training and advice to non-background farmers in the Sydney basin English” NSW Department of Primary Industries, Gosford Horticultural Institute, pp.1-8, 2010.

[7] DORA L, SALAZAR, “An inquiry into a model for normalista preparation and transfer program to the Texas bilingual education teacher program” Texas Tech University, pp. 1-430, 2003.

[8] Magdy M. Kabeil, "Perceived requirements of MIS curriculum implementation in bilingual developing countries” Journal of Information Technology Education, No. 4, pp. 167-188, 2005.

[9] Shaw N. Gynan, “Official bilingualism in Paraguay, 1995-2001: An analysis of the impact of language policy on attitudinal change” Western Washington University, No.4, pp. 24-41, 2005.

[10] D. Thorburn Burns, Hendrik Deelstra, "Analytical chemistry in Belgium: an historical overview ” Microchimica Acta, Vol.161, No. 1-2, pp. 41-66, 2008.

[11] F. Snchez Rojas and C. Bosch Ojeda, "Effluent analysis in analytical chemistry: an overview” Analytical and Bioanalytical Chemistry, Vol.382 No.4, pp. 978-991, 2005.

[12] R. Nordin, R. Shapiee, S. Suhor, A.R. Mohd Yusof and M.M. Muhamad, “The open ended laboratory for measurement of communication skill for chemical/biochemical engineering students ” Procedia-Social and Behavioral Sciences, Vol. 18, pp.7-12, 2011. 